\title{
Pengembangan Industri Pengolahan Karet Berbasis Uikm di Kabupaten Dharmasraya
}

\author{
Hesty Aisyah* \\ * STMIK Indonesia Padang \\ Program Sistem Informasi \\ Jln. Khatib Sulaiman Dalam No. 1 Padang, Sumatera Barat \\ E-mail: hestyaisyah@stmikindonesia.ac.id
}

\begin{abstract}
Abstrak
Kabupaten Dharmasraya merupakan kawasan industri pengolahan karet terbesar di provinsi Sumatera Barat. Namun potensi tersebut belum diolah secara maksimal karena kurangnya minat investor untuk menanamkan modal dalam rangka pengembangan industri pengolahan karet. Selain itu, disebabkan biaya transportasi yang tinggi menyebabkan rantai pemasaran menjadi panjang dan menaikkan harga jual sampai $50 \%$ dari harga pabrik. Dengan adanya permasalahan tersebut, penelitian ini merumuskan strategi dari hasil kondisi terkini, tren pasar, analisis kelayakan finansial agar dapat menyimpulkan strategi yang tepat untuk Pengembangan Industri Pengolahan Karet Berbasis UIKM di Kabupaten Dharmasraya. Untuk merumuskan strategi pengembangan, beberapa metode penelitian akan digunakan seperti uji regresi dan uji asumsi klasik untuk mengetahui seberapa besar pengaruh atau keterkaitan masing-masing variabel agar penelitian ini bisa layak dijalankan. Dari hasil analisis didapat bahwa strategi prioritas yang dapat menjawab permasalahan ini adalah peningkatan kualitas olahan karet yang dihasilkan petani harus sesuai dengan standar nasional sebagaimana merupakan syarat output dari industri pengolahan di Indonesia.
\end{abstract}

Kata kunci: Strategi Bisnis, Industri Pengolahan

\section{Abstract}

Dharmasraya Regency is the biggest rubber processing industrial areas in the province of West Sumatra. However, this potential has not been optimally processed because of the lack of investor interest to invest in developing the rubber processing industry. Besides, due to high transportation costs, the marketing chain is long and raises the selling price to $50 \%$ of the factory price. Given these problems, this study formulated a strategy based on the results of the latest conditions, market trends, financial feasibility analysis to conclude the right strategy for the Development of the UIKM-Based Rubber Processing Industry in Dharmasraya Regency. To formulate development strategies, several research methods will be used such as regression tests and classic assumption tests to find out how much influence or interrelation of each variable so that this research can be feasible to run. From the results of the analysis, it was found that the priority strategy that can address this problem is the improvement of the quality of processed rubber produced by farmers must comply with national standards as a condition of the output of the processing industry in Indonesia.

Keywords: Business Strategy, Manufacturing Industry

\section{Pendahuluan}

Di kawasan pedesaan UIKM (Usaha Industri Kecil dan Menengah masih sangat berpengaruh dalam penciptaan lapangan pekerjaan yang akan berdampak pada penurunan angka kemiskinan di pedesaan. Selain pekerjaan utama,banyak warga di pedesaan yang masih mengandalkan UIKM ini untuk menambah pendapatannya, karena UIKM termasuk pekerjaan yang tidak terlalu membutuhkan kemampuan khusus dalam pengerjaannya (Nurdiyanto \& Meilia, 2016).

Secara umum di Sumatera Barat sektor UIKM masih bersifat Agricultural Based karena Sumatera Barat kaya akan hasil pertanian yang mudah untuk diolah dalam skala kecil dan menengah. Salah satu komoditas yang paling banyak diproduksi oleh UIKM di Sumatera Barat adalah karet. Sebagai kawasan yang masih banyak dikelilingi oleh pepohonan karet 
membuat beberapa kabupaten menjadikan ini sebuah oeluang untuk bisa diproduksi pada industri mereka, salah satunya adalah Kabupaten Dharmasraya. Berdasarkan data dari Badan Pusat Statistik (BPS) Dharmasraya, Kabupaten Dharmasraya, pada tahun 2018 jumlah kepala keluarga yang melakukan usaha tani karet mencapai $35.500 \mathrm{KK}$ dan pada tahun 2018 total luas areal tanaman karet di Kabupaten Dharmasraya adalah 40.927 Ha (BPS, 2018).

Petani karet di Kabupaten Dharmasraya sangat menggantungkan kehidupan mereka pada komoditas ini karena usaha ini merupakan warisan yang sudah turun temurun dan karena adanya dukungan jumlah populasi karet itu sendiri, hanya saja disayangkan kesejahteraan petani karet masih memprihatinkan. Salah satu penyebabnya adalah karena adanya kekuatan Imperfect Market Competition yaitu suatu keadaan dimana harga jual yang seharusnya ditetapkan oleh petani karet tidak berlaku, sehingga eksportir lah yang menetapkan harga jual dari komoditas karet itu sendiri (Brando, Coe, DeFries, \& Azevedo, 2013). Selain itu harga produk olahan karet juga menjadi mahal ketika berada di pasar yang kemudian memberatkan konsumen karena terjadinya rantai pemasaran yang panjang. Kenaikan harga bahan bakar berdampak pada kenaikan biaya transportasi (Novia, Zakaria, \& Lestari, 2013).

Dengan adanya semua permasalahan ini, maka perlu dilakukan pengembangan industri pengolahan karet di tingkat petani. Dengan adanya perencanaan ini diharapkan hasil olahan karet di Kabupaten Dharmasraya bisa meningkatkan nilai tambah di tingkat petani itu sendiri dan mampu mendorong perkembangan industri hilir karet.

\section{Kajian Teori, Literatur, dan Pengembangan Hipotesis}

\section{Pengertian Perencanaan/ Strategi}

Perencanaan adalah sebuah proses untuk mempersiapkan seluruh kegiatan-kegiatan yang akan dilakukan secara sistematis untuk mencapai suatu tujuan dengan menggunakan segala potensi sumbersumber yang dimiliki demi terwujudnya produktivitas (Djamali \& Betaubun, 2018).

Sementara itu menurut Undang-Undang Nomor 25 Tahun 2004 tentang Sistem Perencanaan Pembangunan Nasional, dikatakan bahwa perencanaan adalah sebuah strategi untuk menentukan langkahlangkah yang akan ditetapkan di masa depan secara sistematis dan memperhitungkan ketepatan sumber daya yang ada, agar tujuan ini tercapai maka segala perencanaan ini dirumuskan oleh badan atau instansi yang berkompeten di dalam perencanaan nasional (Rustiadi, 2018).

\section{Konsep Agroindustri dan Prospek Pengembangan}

Menurut Istilah agroindustri berasal dari dari dua kata, yaitu agricultural dan industry yang memiliki makna berjalannya suatu industri yang mengolah produk-produk hasil pertanian untuk dijadikan produk yang bernilai jual tinggi dalam bentuk jadi atau setengah jadi (Sheng, Jackson, Zhao, \& Zhang, 2017). Terdapat dua jenis agroindustri, yaitu:

a) Agroindustri Hulu, yaitu suatu industri yang melakukan kegiatan pengadaan dan penyaluran sarana produksi, dan alat mesin pertanian

b) Agroindustri hilir, yaitu suatu industri yang melakukan kegiatan pengolahan produk-produk pertanian

Untuk jenis agroindustri hilir, industri ini dibagi lagi berdasarkan tingkat pengolahan bahan baku yang disajikan pada Tabel 1 dibawah ini.

TABEL 1

PENGELOMPOKKAN AgROINDUSTRI HILIR BERDASARKAN TINGKAT PENGOLAHAN BAHAN BAKU

\begin{tabular}{|c|c|c|c|c|}
\hline \multirow{2}{*}{ Uraian } & \multicolumn{4}{|c|}{ Tingkat Pengolahan } \\
\hline & I & II & III & IV \\
\hline $\begin{array}{l}\text { I. } \\
\text { Kegiatan } \\
\text { Pengolah } \\
\text { an }\end{array}$ & $\begin{array}{l}\text { Members } \\
\text { ihkan; } \\
\text { Standaris } \\
\text { asi }\end{array}$ & $\begin{array}{l}\text { Memoton } \\
\text { g; } \\
\text { Mencam } \\
\text { pur; } \\
\text { Menggili } \\
\text { ng }\end{array}$ & $\begin{array}{l}\text { Memasak; } \\
\text { Pengalenga } \\
\text { n; } \\
\text { Pasteurisasi } \\
\text {; } \\
\text { Ekstraksi }\end{array}$ & $\begin{array}{l}\text { Pengubah } \\
\text { an sifat- } \\
\text { sifat } \\
\text { kimiawi; } \\
\text { Pengubah } \\
\text { an sifat } \\
\text { asal }\end{array}$ \\
\hline $\begin{array}{l}\text { II. } \\
\text { Contoh } \\
\text { Produk } \\
\text { yang } \\
\text { Dihasilk } \\
\text { an }\end{array}$ & $\begin{array}{l}\text { Buah } \\
\text { Segar; } \\
\text { Sayuran } \\
\text { Segar; } \\
\text { Telur }\end{array}$ & $\begin{array}{l}\text { Daging; } \\
\text { Pakan } \\
\text { Ternak; } \\
\text { Beras }\end{array}$ & $\begin{array}{l}\text { Buah } \\
\text { Kaleng; } \\
\text { Minyak; } \\
\text { Gula }\end{array}$ & $\begin{array}{l}\text { Makanan } \\
\text { Jadi }\end{array}$ \\
\hline
\end{tabular}

Sumber: Sheng (2017)

\section{Prospek Pengembagan Agroindustri}

Indonesia merupakan sebuah negara dengan hasil pertaniannya yang melimpah, karena itu dalam pengembangan UIKM sektor pertanian maka dirasa akan memiliki prospek yang besar. Namun dalam perjalanannya, muncul beberapa faktor penghambat yang mempengaruhi perkembangan UIKM agroindustri (Serrenho, Warr, Sousa, Ayres, \& Domingos, 2016). Faktor-faktor tersebut adalah:

1. Terjadinya reorientasi kebijaksanaan pengembangan nasional yang berkaitan dengan pengembangan agroindustri.

2. Keterbatasan infrastruktur agroindustri yang pada akhirnya mengurangi minat investor untuk menanamkan modalnya.

3. Agroindustri merupakan sebuah usaha yang memiliki resiko tinggi, seperti perubahan musim yang tidak menentu, hasil panen yang tidak bisa dipastikan karena diserang hama, dll.

Untuk menanggulangi segala macam kemungkinan kendala yang timbul dan berdampak pada melemahnya perkembangan agroindustri, maka 
pihak pemerintah perlu mengetahui segala prioritas dan potensi yang dimiliki setiap daerah di Indonesia, hal ini bertujuan agar agroindustri bisa berkembang sesuai dengan profil keadaan dan kemampuan daerah masingmasing.

\section{Konsep Usaha Industri Kecil dan Menengah (UIKM)}

Definisi Industri menurut Undang-Undang Nomor 9 Tahun 1995, industri kecil dan menengah adalah entitas industri yang memiliki kekayaan bersih paling banyak 200 juta, tidak termasuk tanah dan bangunan tempat usaha, memiliki penjualan tahunan paling banyak Rp. 1 Milyar untuk industri kecil sampai Rp. 10 Milyar untuk industri menengah, dan memiliki karyawan berkisar 5-9 orang untuk industri kecil dan 20-99 orang untuk industri menengah (Nurdiyanto \& Meilia, 2016).

UIKM sebagai motor penggerak pengolahan hasil pertanian memiliki beberapa perana penting dalam meningkatkan kesejahteraan masyarakat daerah, yaitu:

1. Dalam kegiatan banyak memerlukan SDM sehingga bisa menekan jumlah pengangguran di daerah setempat.

2. Tidak terlalu membutuhkan investasi besar pada tahap awal kegiatan industri.

3. Dalam rangka pengembangan usaha tidak terlalu memerlukan ketrampilan khusus, sehingga relatif mudah dalam mencapai target penjualan.

4. Prioritas utama dari kebijakan pembangunan kabupaten Dharmasraya sebagai ujung tombak penguatan dan pengembangan ekonomi masyarakat.

\section{Industri Pengolahan Karet berbasis UIKM}

Pembangunan industri pengolahan karet di Kabupaten Dharmasraya dianggap akan berhasil jika memerhatikan unsur-unsur penting berikut ini:

\section{Lokasi}

Pada tahap awal mendirikan usaha, industri pengolahan karet harus memperhatikan kondisi lingkunagn sekitar industri. Lokasi Industri harus diusahakan dekat dengan sumber air, karena air merupakan bahan baku utama dalam kegiatan industri ini, ketersediaan infrastruktur jalan juga harus diperhatikan untuk mempermudah kegiatan operasi industri.

\section{Bahan Baku}

Bahan baku yang diperlukan harus tersedia secara maksimal sesuai dengan kebutuhan proses produksi

\section{Fasilitas Produksi}

Fasilitas produksi yang terdiri dari bangunan tempat usaha, mesin peralatan harus disediakan mulai 76 | Jurnal Akuntansi, Ekonomi dan Manajemen Bisnis | dari tahap awal produksi penumpukan bahan karet mentah sampai barang jadi.

\section{Tenaga Kerja}

Tenaga kerja untuk industri sektor ini tidak terlalu memerlukan keahlian khusus. Penentuan jumlah tenaga kerja yang diperlukan bisa disesuaikan dengan target proses produksi per periodenya.

\section{Proses Produksi}

Proses produksi yang dilakukan untuk mengolah bahan baku karet dimulai dari menyortir bahan baku,, pemotongan, penghancuran, penggilingan, sampai proses pengeringan (Boerhendhy, Nancy, \& Gunawan, 2018).

\section{Kerangka Pemikiran}

Kerangka pemikiran penelitian ini dimulai dari rendahnya harga karet di tingkat petani sehingga diperlukan peningkatan nilai tambah agar pendapatan petani bisa meningkat. Kemudian langkah selanjutnya adalah melakukan analisa kondisi eksisting karet alam di Kabupaten Dharmasraya dengan menggunakan variabel aspek harga, aspek produksi, dan aspek tenaga kerja. Setelah itu, untuk mengetahui perumusan kebijakan dan strategi dilakukan analisa menggunakan rangkuman dari kondisi eksisting dan tren pasar.

\section{Perumusan Hipotesis}

Pada pasar dalam negeri, diduga variabel harga jual karet di pasaran dunia berpengaruh positif dan signifikan terhadap harga beli karet di tingkat petani pada Kabupaten Dharmasraya. Nilai $\beta 1<1$ menunjukkan bekerjanya mekanisme pasar persaingan tidak sempurna.

\section{Metode Penelitian}

\section{Jenis dan Sumber Data}

Penelitian ini menggunakan dua jenis sumber data, yaitu:

1. Data Primer, diperoleh dari beberapa perusahaan yang terdapat pada Industri Pengolahan Karet berbasis UIKM di Kabupaten Dharmasraya dengan cara Indepth Interview.

2. Data sekunder adalah data diperoleh dari literatur yang terkait dengan kajian penelitian baik studi literatur, hasil penelitian terdahulu, Badan Pusat Statistik Indonesia, dan dari situs website Kementerian yang terkait.

\section{Populasi dan Sampel Penelitian}

Penelitian ini mengambil objek penelitian di daerah Kabupaten Dharmasraya Provinsi Sumatera Barat. Kawasan ini diambil karena Kabupaten Dharmasraya merupakan sentra produksi terbesar di Sumatera Barat (BPS, 2018). Jumlah perusahaan skala 
UIKM yang terdapat pada kawasan Industri pengolahan di Kabupaten Dharmasraya berjumlah 289 unit.

Adapun metode pengambilan sampel yang digunakan pada penelitian ini adalah dengan menggunakan rumus slovin, yaitu sebagai berikut:

Dimana:

$$
n=\frac{\mathrm{N}}{1+\mathrm{N} e^{2}}
$$

$\mathrm{n} \quad=$ Jumlah Sampel

$\mathrm{N}=$ Populasi

$\mathrm{E}=$ Margin error

$1=$ Bilangan Konstan

Berdasarkan rumus diatas maka didapatkan:

$$
n=\frac{289}{1+289(0,1)^{2}}=74,29
$$

Sehingga jumlah sampel untuk penelitian ini sebanyak 74 unit usaha.

\section{Definisi Operasional Variabel} adalah:

Definisi operasional variabel dalam penelitian ini

1. Harga jual karet di pasar internasional yang diperoleh dari situs resmi Kementerian Perindustrian (Kemenperin) adalah harga jual yang berlaku di pasaran dunia setelah dikurangi pajak dan biaya lainnya yang dijadikan dalam satuan $\mathrm{Rp} / \mathrm{kg}$. Jika nilai koefisien $\beta 1<1$ berarti terdapat indikasi yang menunjukkan bekerjanya mekanisme pasar persaingan tidak sempurna (Corchón, 2018).

2. Harga beli karet di tingkat petani di Kabupaten Dharmasraya adalah harga karet yang belum diolah menjadi barang jadi yang dihitung dalam satuan $\mathrm{Rp} / \mathrm{kg}$. Harga beli karet merupakan harga rata-rata pertahun dari tahun 2010 sampai tahun 2018 yang diperoleh dari Dinas Perkebunan Sumatera Barat.

\section{MetodeAnalisis Data}

Beberapa metode analisis data yang dipakai dalam penelitian ini adalah sebagai berikut:

1. Untuk mengetahui kondisi eksisting karet alam di Kabupaten Dharmasraya dilihat dari aspek harga, aspek produksi, dan aspek tenaga kerja dilakukan analisa pengaruh masingmasing aspek dengan harga bersih penjualan di tingkat eksportir dengan menggunakan persamaan regresi sederhana, yaitu:

$$
Y=\beta_{0}+\beta_{1} X_{1}+\varepsilon
$$

$\mathrm{Y}=$ Harga beli karet di tingkat petani di Kabupaten Dharmasraya dalam Rp/ kg

$X_{1}=$ Harga jual karet di pasar internasional adalah harga jual yang berlaku di pasaran dunia setelah dikurangi pajak dan biaya lainnya dalam Rp/ kg

$\beta_{0}=$ Konstanta

$\beta_{1}=$ Koefisien Regresi

2. Untuk mengetahui tren pasar hasil produksi karet alam dilihat dari aspek produksi dalam pengembangan industri pengolahan karet berbasis UIKM di Kabupaten Dharmasraya menggunakan analisis deskriptif kualitatif.

3. Untuk mengetahui apakah hasil regresi tidak mengalami penyimpangan, maka perlu dilakukan uji asumsi klasik. Asumsi-asumsi klasik yang harus dipenuhi yaitu Uji normalitas, Uji multikolinearitas, Uji autokorelasi, dan Uji heteroskedastisitas dengan menggunakan alat atau software analisis SPSS versi 16

3. Untuk merumuskan kebijakan pengembangan dan strategi yang perlu diterapkan dalam Industri Pengolahan Karet berbasis UIKM di Kabupaten Dharmasraya dilakukan berdasarkan peninjauan dan pengamatan dari hasil kondisi eksisting karet alam dan tren pasar yang dipengaruhi aspek harga, produksi, dan tenaga kerja.

\section{Analisa dan Pembahasan}

\section{Produksi Karet}

Perkebunan karet di Kabupaten Dharmasraya merupakan perkebunan yang dikelola sepenuhnya oleh masyarakat setempat. Pada umumnya perkebunan ini memiliki produktivitas rata-rata $3.255 \mathrm{~kg}$ per hektar dalam setiap tahunnya. Luas lahan yang digunakan mengalami peningkatan setiap tahunnya, ini disebabkan salah satunya karena perkebunan ini merupakan pekerjaan yang bisa membawa kesejahteraan ekonomi bagi masyarakat sekitar.

\section{Analisis Kondisi Eksisiting Pasar dari Aspek Harga}

Aspek harga dilakukan untuk menguji dan menganalisa pengaruh antara harga jual karet di tingkat eksportir terhadap harga di tingkat petani karet dengan menggunakan analisis regresi sederhana.

Hasil regresi sederhana dengan menggunakan metode OLS terhadap data time series tahun 2010-2018 diperoleh $\mathrm{r}=0,87 ; \beta_{0}=-401,45 ; \beta_{1}=0,72$. Dengan hasil persamaan interprestasi yang diolah menggunakan metode OLS, sebagai berikut:

1. Tanda negatif untuk konstanta merupakan tanda yang menunjukkan bahwa petani masih sangat tergantung dengan eksportir. Jika diasumsikan tidak ada penjualan karet di pasar internasional maka harga beli karet di tingkat petani

Dimana:

77 | Jurnal Akuntansi, Ekonomi dan Manajemen Bisnis | Vol. 8 No.1, July 2020, 74-81 | E-ISSN: 2548-9836 
Kabupaten Dharmasraya menjadi Rp -401,45 per kg, artinya jika tidak ada kegiatan di tingkat eksportir, maka industri karet bisa terhenti karena petani akan terbebani dengan biayabiaya produksi sementara kegiatan penjualan tidak ada.

2. Tanda positif dari koefisien parameter menunjukkan bahwa harga karet mempunyai pengaruh positif terhadap harga beli karet di tingkat pedagang perantara. Artinya, jika diasumsikan harga jual karet mengalami kenaikan di pasar internasional sebesar Rp 1 per $\mathrm{kg}$ maka harga beli karet di tingkat petani Kabupaten Dharmasraya akan naik sebesar Rp 0,72 per kg. Dari hasil pengujian pada tingkat kesalahan $5 \%$ dari parameter yang diestimasi dengan menggunakan uji $\mathrm{t}$ yang diperoleh dari perhitungan SPSS pada Coefficient Regression. Dari hasil uji $t$ tersebut didapat nilai $t$ hitung lebih besar dari t tabel $(2,86>0,522)$, dari hasil tersebut bisa dimpulkan bahwa terdapat pengaruh yang signifikan antar masing-masing variabel. Untuk koefisien parameter $\beta_{1}$ juga signifikan secara statistik, nilai $\beta_{1} \neq 1$ dimana memiliki nilai $<1$ yakni sebesar 0,72 . Hal ini berarti bekerjanya mekanisme pasar persaingan tidak sempurna. Nilai $\beta_{1}$ yang jauh dari 1 menunjukkan ketidak efisienan pasar. Tingkat efisiensi pasar dan harga komoditas karet di daerah merupakan aspek yang sangat besar pengaruhnya terhadap semangat masyarakat untuk bekerja dan berusaha di sektor pengolahan karet.

\section{Analisis Kondisi Eksisiting Pasar dari Aspek Produksi}

Aspek produksi dengan menghitung dan menganalisa rasio konsentrasi posisi produksi karet di Kabupaten Dharmasraya dengan beberapa kabupaten di Sumatera Barat. Kabupaten yang dipilih merupakan kabupaten yang memiliki jumlah produksi karet terbanyak di provinsi Sumatera Barat. Hasil perhitungan rasio konsentrasi produksi karet dapat dilihat pada Tabel 2 .

TABEL 2

Rasio Konsentrasi Produksi KaRET di PROPINSI SUMATERA

BARAT DALAM PERSEN (\%) TAHUN 2014-2018

\begin{tabular}{|c|c|c|c|c|c|c|}
\hline \multirow{2}{*}{ Kab. } & \multicolumn{5}{|c|}{ Tahun } & Rata- \\
\cline { 2 - 7 } & 2014 & 2015 & 2016 & 2017 & 2018 & rata \\
\hline $\begin{array}{c}\text { Dharmasra } \\
\text { ya }\end{array}$ & 28,2 & 29,5 & 32,7 & 33,4 & 34,9 & 31,7 \\
\hline Sijunjung & 20,4 & 21,2 & 19,5 & 20,7 & 22,3 & 20,8 \\
\hline Pasaman & 9,8 & 10,2 & 11,3 & 10,8 & 11,4 & 10,7 \\
\hline Solok & 8,4 & 8,9 & 9,2 & 8,9 & 9,5 & 8,9 \\
\hline
\end{tabular}

\begin{tabular}{|c|c|c|c|c|c|c|}
\hline 50 Kota & 6,2 & 7,8 & 8,9 & 8,8 & 9,1 & 8,1 \\
\hline
\end{tabular}

Sumber: Data diolah

Tabel 2 memperlihatkan rasio konsentrasi produksi karet beberapa kabupaten di Sumatera Barat. Persentase pada tabel tersebut memperlihatkan kemampuan masing-masing kabupaten dalam penguasaan pasar komoditi karet yang dilihat dari volume produksi karet per tahun. Kabupaten Dharmasraya menempati posisi paling atas kemudian disusul Kabupaten Sijunjung yang sama-sama memiliki persentase rata-rata diatas $20 \%$. Untuk Kabupaten lainnya masing memiliki rasio konsentrasi dibawah $10 \%$.

Untuk Kabupaten Dharmasraya sendiri, rasio konsentrasinya tiap tahun selalu mengalami peningkatan, ini disebabkan salah satunya karena adanya peningkatan volume tanaman karet yang akan diproduksi, selain juga disebabkan karena adanya penambahan luas lahan per tahunnya.

Selain membandingkan posisi produksi karet di Kabupaten Dharmasraya dengan kabupaten lainnya, kemudoa dilakukan pula perbandingan antara luas tanaman karet antar kabupaten-kabupaten tersebut. Hasil perhitungan rasio luas tanaman karet dapat dilihat pada Tabel 3.

TABEL 3

RASIO KONSENTRASI LUAS TANAMAN KARET DI BEBERAPA

KABUPATEN Di SUMATERA BARAT DALAM (\%) TAHUN 2014-2018

\begin{tabular}{|c|c|c|c|c|c|c|}
\hline \multirow{2}{*}{ Kab. } & \multicolumn{5}{|c|}{ Tahun } & Rata- \\
\cline { 2 - 7 } rata \\
\cline { 2 - 7 } & 2014 & 2015 & 2016 & 2017 & 2018 & 33,7 \\
\hline $\begin{array}{c}\text { Dharmasra } \\
\text { ya }\end{array}$ & 32,8 & 33,2 & 33,8 & 34,0 & 35,1 & $33,2,3,2$ \\
\hline Sijunjung & 25,1 & 26,4 & 26,7 & 25,1 & 24,3 & 25,5 \\
\hline Pasaman & 13,5 & 13,8 & 14,2 & 14,4 & 15,3 & 14,2 \\
\hline Solok & 2,5 & 2,8 & 3,3 & 4,2 & 3,8 & 3,3 \\
\hline 50 Kota & 2,2 & 2,5 & 3,0 & 3,2 & 3,4 & 2,8 \\
\hline
\end{tabular}

Sumber: Data diolah

Tabel 3 memperlihatkan rasio konsentrasi luas tanaman karet beberapa kabupaten di propinsi Sumatera Barat. Terdapat 3 kabupaten di Sumatera Barat yang melebihi $10 \%$ per tahunnya, yaitu Kabupaten Dharmasraya, Sijunjung, dan Pasaman. Kabupaten Dharmasraya memiliki rasio paling besar yaitu 33,7\% dari tahun 2014 sampai 2018, artinya kemampuan penguasaan lahan komoditi karet di Dharmasraya adalah yang paling terbesar.

\section{Analisis Kondisi Eksisiting Pasar dari Aspek Tenaga Kerja}

Kondisi eksisting pasar yang dilihat dari aspek tenaga kerja diukur berdasarkan rasio konsentrasi dari sudut penyerapan tenaga kerja di subsektor perkebunan

78 | Jurnal Akuntansi, Ekonomi dan Manajemen Bisnis | Vol. 8 No.1, July 2020, 74-81 | E-ISSN: 2548-9836 
karet, khususnya perkebunan karet di beberapa kabupaten di Sumatera Barat pada tahun 2018 yang dapat dilihat dalam Tabel 4.

TABEL 4

JUMLAH PETANI KARET DAN RASIO KONSENTRASI (\%) BEBERAPA

KABUPATEN DI SUMATERA BARAT TAHUN 2018

\begin{tabular}{|c|c|c|c|}
\hline No & Kabupaten & $\begin{array}{c}\text { Petani Karet } \\
(\mathrm{KK})\end{array}$ & $\begin{array}{c}\text { Rasio } \\
\text { konsentrasi } \\
(\%)\end{array}$ \\
\hline 1 & Dharmasraya & 42.889 & 24,5 \\
\hline 2 & Sijunjung & 30.266 & 20,7 \\
\hline 3 & Pasaman & 23.905 & 17,8 \\
\hline 4 & Solok & 16.670 & 8,7 \\
\hline 5 & 50 Kota & 10.233 & 5,6 \\
\hline
\end{tabular}

Sumber: Data diolah

Sesuai dengan Tabel 4 dapat disimpulkan bahwa penyerapan tenaga kerja di sektor perkebunan karet di Dharmasraya masih menempati urutan tertinggi dibandingkan dengan kabupaten lainnya, hal tersebut juga dipengaruhi karena adanya penambahan luas lahan perkebunan karet di Dharmasraya.

\section{Tren Pasar Hasil Produksi Karet Alam}

Tren pasar hasil produksi karet alam dapat dilihat dari aspek produksi karet dalam pengembangan industri pengolahan karet berbasis UIKM di Kabupaten Dharmasraya.

Saat ini petani karet di Dharmasraya terdata paling banyak memproduksi karet alam untuk dijadikan bahan olahan karet dalam bentuk ojol. Produksi ojol yang dihasilkan oleh petani karet sejak tahun 2014 sampai 2018 dapat dilihat pada Gambar 1.

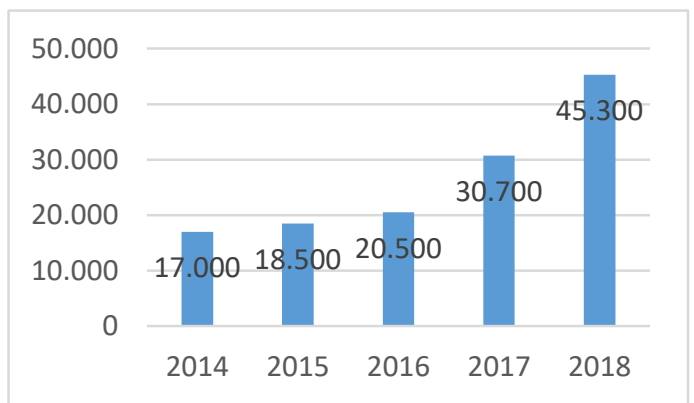

Gambar 1. Perkembangan Produksi Ojol di Kabupaten Dharmasraya

Pada Gambar 1, dapat dilihat bahwa produksi ojol di Kabupaten Dharmasraya mengalami peningkatan secara stagnan dari tahun 2014 sampai 2018. Produksi ojol di Dharmasraya tersebar di beberapa kecamatan seperti Kecamatan Sungai Rumbai, Koto Besar, Koto Baru, Koto Salak, dll.

\section{Hasil Uji Asumsi Klasik}

a) Uji Normalitas

Uji normalitas digunakan untuk mengetahui apakah variabel dependen dan independen berdistribusi secara normal atau tidak. Penelitian ini menggunakan analisa dari nilai skewness dan kurtosis melalui software SPSS versi 16 untuk mengukur uji normalitas.

TABEL 5

HASIL UJI NORMALITAS

Descriptive Statistics

\begin{tabular}{|r|r|r|r|}
\hline \multicolumn{2}{|c|}{ Skewness } & \multicolumn{2}{c|}{ Kurtosis } \\
\hline Stat & Std. error & Stat. & Std. Error \\
\hline .086 & .097 & .134 & .189 \\
& & & \\
\hline
\end{tabular}

a. Dependent Variable: $Y$

Dari data pada Tabel 5 diatas, diperoleh hasil hasil $\mathrm{Z}$ skewness dan $\mathrm{Z}$ kurtosis lebih kecil dari nilai Z untuk taraf signifikansi 5\%. Dari hasil tersebut bisa disimpulkan bahwa data pada penelitian ini terdistribusi secara normal.

b) Uji Multikolinearitas

TABEL 6

HASIL Uji MULTIKOLINEARITAS

Coefficients $^{a}$

\begin{tabular}{|ll|r|r|}
\hline \multicolumn{2}{|c|}{} & \multicolumn{2}{|c|}{ Collinearity Statistics } \\
\cline { 3 - 4 } \multicolumn{2}{|l|}{ Model } & Tolerance & \multicolumn{1}{c|}{ VIF } \\
\hline 1 & (Constant) & & \\
& $\mathrm{X}$ & 0,877 & 1.240 \\
\hline
\end{tabular}

a. Dependent Variable: $Y$

Dari Tabel 6 dapat dilihat, bahwa variabel independen memiliki nilai Variance Inflation Factor (VIF) sebesar 1,240 yang berada di antara rentang 1 sampai 10. Begitupun juga dengan nilai Tolerancenya yang mendekati nilai 1. Dari hasil interpretasi ini bisa disimpulkan bahwa penelitian ini tidak mengalami masalah multikolinearitas. 


\section{c) Uji Autokorelasi}

TABEL 7

HASIL UJI AUTOKORELASI

\begin{tabular}{|l|c|c|c|c|r|}
\hline Model & \multicolumn{1}{|c|}{ Model Summary } \\
\hline 1 & $.924 \mathrm{a}$ & $\mathrm{R}$ Square & $\begin{array}{c}\text { Adjusted } \mathrm{R} \\
\text { Square }\end{array}$ & $\begin{array}{c}\text { Std. Error of the } \\
\text { Estimate }\end{array}$ & Durbin-Watson \\
\hline
\end{tabular}
a. Predictors: (Constant), $\mathrm{X}$
b. Dependent Variable: $\mathrm{Y}$

Dari Tabel 7 dapat dilihat, bahwa nilai Durbin Watson memperoleh nilai 2,8 dimana hasil ini masih mendekati angka 2. Dari hasil interpretasi ini bisa disimpulkan bahwa penelitian ini tidak mengalami masalah autokorelasi.

\section{d) Uji Heteroskedastisitas}

TABEL 8

HASIL UJI HETEROSKEDASTISITAS

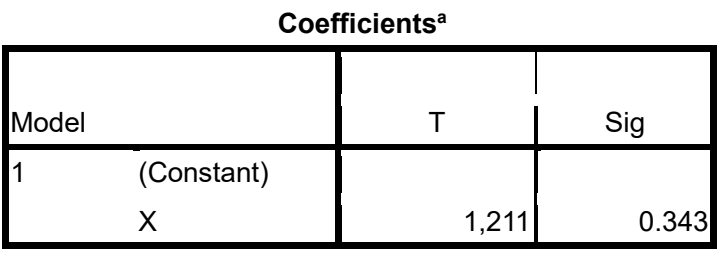

a. Dependent Variable: $Y$

Dari Tabel 8, bisa dilihat bahwa nilai signifikansi lebih besar dari tingkat kesalahan $5 \%(0,343>0,01)$. Jadi bisa disimpulkan bahwa penelitian ini bebas dari masalah heteroskedastisitas.

\section{Perencanaan Industri Pengolahan Karet Berbasis UIKM di Kabupaten Dharmasraya}

Hasil analisis kondisi eksisting karet alam di Kabupaten Dharmasraya dilihat dari aspek harga karet di tingkat petani, aspek posisi produksi karet, dan penyerapan tenaga kerja subsektor perkebunan di Kabupaten Dharmasraya menunjukkan hasil yang mendukung perlunya perencanaan pengembangan industri pengolahan karet di Dharmasraya.

Dari keseluruhan faktor aspek-apek yang mempengaruhi dan tren pasar, mendirikan industri crumb rubber memiliki peluang pasar yang besar karena petani karet di kabupaten Dharmasraya banyak memproduksi karet mentah menjadi ojol yang selalu digunakan untuk pembuatan crumb rubber.

Selain itu, industri pengolahan karet baiknya juga dikembangkan secara merata di seluruh kecamatan di Kabupaten Dharmasraya yang potensial, agar jumlah produksi bisa terus meningkat dan bisa menyeimbangi permintaan pasar akan karet dan produk olahannya.

Besarnya produksi akan berpengaruh pada peningkatan pendapatan petani karet, dan juga berpengaruh terhadap pendapatan pengusaha karet sebagai pemilik usaha industri pengolahan karet, sehingga hal-hal seperti biaya transportasi yang sedikit membebani mereka akan berkurang.

\section{Kesimpulan}

Dari hasil analisis kondisi eksisting karet alam di Kabupaten Dharmasraya dilihat dari aspek harga karet di tingkat petani, aspek posisi produksi karet, dan penyerapan tenaga kerja subsektor perkebunan di Kabupaten Dharmasraya diperoleh beberapa strategi pengembangan, yaitu:

1. Peningkatan kualitas SDM yakni para petani karet dengan cara sosialisasi yang dilakukan oleh pemerintah terkait dengan penerapan aplikasi teknologi tepat guna dalam rangkan peningkatan mutu produksi.

2. Melakukan perluasan akses usaha sehingga akan jaringan akses pasar akan terjangkau secara luas.

3. Meningkatkan produktivitas tanaman karet untuk meningkatkan jumlah pasokan produksi karet, seiring dengan penambahan luas lahan yang selalu terjadi secara stagnan tiap tahunnya.

\section{References}

A. Boerhendhy, I., Nancy, C., \& Gunawan, A. (2018) Prospek dan potensi pemanfaatan kayu karet sebagai substitusi kayu alam. Jurnal Ilmu Dan Teknologi Kayu Tropis, 1(1), 35-46.

B. BPS. (2018). Dharmasraya Dalam Angka 2018.

C. Brando, P. M., Coe, M. T., DeFries, R., \& Azevedo, A. A. (2013). Ecology, economy and management of an agroindustrial frontier landscape in the southeast Amazon. The Royal Society.

D. Corchón, L. C. (2018). Imperfectly competitive markets, trade unions and inflation: Do imperfectly competitive markets transmit more inflation than perfectly competitive ones? A theoretical appraisal. A Theoretical Appraisal (October 18, 2018).

E. Djamali, R. A., \& Betaubun, P. (2018). Key Factors on Development of Agricultural and Fishery Agroindustry Classification in Merauke Regency. International Journal of Mechanical Engineering and Technology (IJMET), 9(10), 295-303.

F. Novia, W., Zakaria, W. A., \& Lestari, D. A. H. 80 | Jurnal Akuntansi, Ekonomi dan Manajemen Bisnis | Vol. 8 No.1, July 2020, 74-81 | E-ISSN: 2548-9836 
(2013). Analisis nilai tambah dan kelayakan pengembangan agroindustri beras siger. Jurnal Ilmu-Ilmu Agribisnis, 1(3), 210-217.

G. Nurdiyanto, H., \& Meilia, H. (2016). Sistem Pendukung Keputusan Penentuan Prioritas Pengembangan Industri Kecil Dan Menengah Di Lampung Tengah Menggunakan Analitical Hierarchy Process (AHP). SEMNASTEKNOMEDIA ONLINE, 4(1), 3.

H. Rustiadi, E. (2018). Perencanaan dan pengembangan wilayah. Yayasan Pustaka Obor Indonesia.

I. Serrenho, A. C., Warr, B., Sousa, T., Ayres, R. U., \& Domingos, T. (2016). Structure and dynamics of useful work along the agriculture-industryservices transition: Portugal from 1856 to 2009. Structural Change and Economic Dynamics, 36, $1-21$.

J. Sheng, Y., Jackson, T., Zhao, S., \& Zhang, D. (2017). Measuring Output, Input and Total Factor Productivity in Australian Agriculture: An Industry-Level Analysis. Review of Income and Wealth, 63, S169-S193. 